\title{
Analysis on the Phenomenon of "Craze for Mo Yan" and Cultural Teaching in International Chinese Education
}

\author{
Xu Xiang \\ College of Humanities \\ Xi'an Peihua University \\ China 710125 \\ 37428864@qq.com
}

\begin{abstract}
In the view of globalization, it should pay much attention to spread Chinese culture in international Chinese education while imparting language knowledge. The phenomenon of "craze for Mo Yan" has been formed in China or even overseas since Mo Yan won the Nobel Prize in literature. His works have become an extremely effective medium in cultural education. Through the interpretation of his works, this paper analyzes the contents of native culture and literary vision with global characteristics and discusses how his works to promote the spread of Chinese culture globally and the specific application in Chinese te aching, which is of gre at significance to study in the field of international Chinese education.
\end{abstract}

Keywords-craze for Mo Yan, international Chinese education, culture, teaching

\section{INTRODUCTION}

The consensus has been reached on the idea that the spread of culture, in some sense, is an important goal for international Chinese education. The successful international Chinese education should not be simply restricted in teaching Chinese. It is of great importance to spread Chinese culture. To some extent, "language education and cultural inheritance and dissemination complement each other in which language acts as bridge and culture serves as boats."[1] At present, the international promotion of Chinese is an essential part of national cultural strategy. Chinese culture should actively go out and so does the Chinese language, which is the inevitable requirement for the exchange between China and western countries, the construction of Chinese cultural image and the formation of world multi-culture pattern. 'Language is the carrier and teaching is the medium. And what we spread is the culture and its values of various country."[2] In the era of globalization, many countries attach great importance to the output of native culture and even include it into national strategy. Native culture and the spread of value can enhance international status of a country, which is typically exemplified by Confucius institute overseas. Thereupon, which Chinese culture should be spread to foreign learners and in what forms? This is worthy of thinking.

As a part of culture, literature is an extremely effective medium for cultural teaching. Literature itself carries the contents of culture. To teach Chinese culture by studying literature is also accepted by foreign learners. In recent years, it is more and more popular to spread Chinese literature overseas including the works of Mo Yan which are widely translated and published in foreign markets and won many awards. Mo Yan himself also won Nobel Prize in literature in 2012. After that, the phenomenon of "craze for Mo Yan" has been formed in China and abroad. Under such background, Mo Yan's works as a tool are very suitable to spread Chinese culture in international Chinese education.

\section{CHINESE FACTORS IN MO YAN'S NOVELS}

Mo Yan is one of the most influential contemporary writers in China. And his works, to certain extent, reproduce the imagination for western readers on China. "The reasons for the little bit of overseas influence of my works may be concluded that my novels are unique, the ideas are special, characters have personalities and languages are individualized, which equip my novels with strong Chinese characteristics. The characters in my novels are indeed born and raised in China. "[3] The important reason for Mo Yan's novels going global is the strong Chinese characteristics.

\section{A. Mo Yan's novel and classic novel}

In the aspect of creation, Mo Yan's novels first of all inherit techniques of Chinese classic novels. To take The Republic of Wine as an example, its plot is very magical and characters are tinged with ghostliness. It has such narrative facts as mystery novels and Tang legends. Strange Stories from a Chinese Studio derived from mystery novels is also Mo Yan's favorite work. The conflict plot between Ximen Nao and Lord Yama, an official in charge of the life-and-death register under the King of Hell in Life and Death are Wearing Me Out draws on the plot of Xi Fangping. As it were, Mo Yan's novels inherit Chinese historical and cultural contexts, especially mysterious culture. In addition, his novels also inherit the narrative technique of Chinese vernacular story which, as an art of talking, is the prototype of spoken language expression. In order to attract the attention of listeners, vernacular story must be told in a brilliant manner. Mo Yan is an expert at storytelling and develops such technique to its fullest in many of his works. Red Sorghum is a wild romantic story about grandfather and grandmother in Dongbei village, Gaomi county. Sandalwood Death tells a story about brutal criminal penalty in ancient time. As a good storyteller, Mo Yan's novels 
embody the art of talking. Most of Mo Yan's novels are about history, which also shows the inheritance and promotion of his novels on historical biography literature. Chinese culture itself contains historical biography tradition, which makes Chinese novels craze for the record of history. The history in Big Breast and Wide Hips spans nearly 100 years, covering hundred years of history in China. Additionally, historical biography tradition is also characterized by the thinking on "filling in the gap of history" for the historical authenticity. Therefore, besides the official history, Chinese unofficial history is also very rich and diversified. Mo Yan adopts such thinking on" filling in the gas of history" in the historical narration of his novels, describing the history in contrast to official ideology from the perspective of folk history, such as Red Sorghum. It is observed that Mo Yan's novels, to a great extent, inherit the technique of classic novels, which is also the traditional culture in his novels.

\section{B. Traditional culture in Mo Yan's novels}

Mo Yan's novels contain lots of traditional and folk culture. Mo Yan describes the vicissitude of Chinese society by using samsara of Buddhism in Death are Wearing Me Out. The name of this novel stems from Buddhist Scriptures and the story is about six realms wheel of life of Ximen Nao. Red Sorghum manifests folk culture in Dongbei village, Gaomi County which is full of strong local feature. The romantic story between grandfather and grandmother reproduces the folk religion full of wild life in loess land with which Mo Yan closely associates. The local flavor and the people and events of homeland unfold before the readers. In Mo Yan's novels, there are various folk customs, such as cat accent, a kind of local opera popular in Gaomi, Shangdong province which appears in Sandalwood Death and Death are Wearing Me Out. Cat accent even serves as plotline in Sandalwood Death. In Red Sorghum, such ceremonies as wedding, paper cuttings and God of Wine worship make people feel the colorful and diversified local customs. What's more, there are also many local dialects in Mo Yan's novels, such as the dialects and two-part allegorical saying in Sandalwood Death.

Mo Yan uses different forms to manifest Chinese traditional culture and interprets Chinese culture in a very vivid manner. His novels, as it were, become a national culture brand with Chinese characteristics. He builds a shared community of imagination of Chinese culture by using his own novels. And his novels not only reproduce original forms of Chinese traditional culture, but also represent the acknowledgement of writers on local culture. 'With regard to 'other', each culture can always trigger some kind of sense of curiosity."[4] From this point of view, the traditional culture in Mo Yan's novels can be applied in cultural teaching in international Chinese education and is very helpful to spread Chinese culture.

\section{GLOBAL FEATURE IN MO YAN'S NOVELS}

We not only needs to emphasize native characteristics to spread Chinese culture but also actively adapt to global cultural context, as exactly exemplified by Mo Yan's novels in which abundant Chinese traditional culture, on the one hand, is included; on the other hand, global feature of literature is very apparent. "Mo Yan unfolds a unique picture scroll for the world literature by writing national characteristics and the attention from the world makes his independent figure stand stably on the ground. "[5] The reasons why Mo Yan won Nobel Prize in literature may be the 'triumph of literature". And Chinese literature per se is a part of world literature. While manifesting local culture, Mo Yan also writes those fundamental things of literature which transcend geography and race in his creation from the perspective of humanity and in artistic expression, he uses the technique of western literature, either, which move both Chinese and foreign readers.

\section{A. Universal theme in Mo Yan's novels}

Mo Yan pays much attention to humanity, a universal theme in his novels. Literature first of all is about human beings. In spite of differences between Chinese and western literature, there are similarities, that is to pay attention to shared destiny of human beings and to raise universal questions through literature. The rural world in northern China described in Red Sorghum is full of local features, but the love of grandfather and grandmother ignorant of all morality, ethics and regulations is free and full of vigor and vitality, which reflects the energy and passion of life. Dongbei Village of Gaomi County in Mo Yan's work is a world where people struggle to survive. Each character is marked by the time, but they have exuberant vitality and strong power of human nature. The free and booming lives are their understanding and pursuit on life. "My grandfather" and "my grandmother" in the novel ignoring so-called morality and ethics have free and vigorous life just like red sorghum. They dare to love and hate and live freely. "My grandfather" Yu Zhanao either kills people and escapes from prison or devotes himself to his country with supreme loyalty. "My grandmother" Dai Fenglian is dismissive of any secular shackles, falling in love wildly with Yu Zhanao in the land of sorghum. They embody the passion of life. The writing on life and humanity in the novel is undoubtedly endowed with the global feature to transcend race and geography.

\section{B. Reference from western artistic technique in Mo Yan's novels}

Besides writing on such universal theme as life and humanity in his novels, Mo Yan also learns from foreign writers and draws on the techniques of western literary creation, which is also the reason why his works are easier to be accepted by foreign readers. "I wrote most of my works in the mid of 1980s to mid of 1990s. I was greatly influenced by western writers, without the stimulation of whose works my hometown novels cannot be activated."[6] Mo Yan's novels are most influenced by Faulkner and Marquez. Most of his novels are set in his hometown Dongbei, Gaomi County, which is a world of art belonging to Mo Yan himself. It was not until Mo Yan created his own art space that he began to become mature in his works. It is obvious that he learned such writing technique from Faulkner who creates Yoknapatawpha in his novels. Inspired by him, Mo Yan also has his own Dongbei, Gaomi County. Faulkner is a world-class master in stream of consciousness novel. And Mo Yan is also good at using the stream of consciousness. The writing on love story of "my grandfather" and "my grandmother" is a typical stream of consciousness. Mo Yan' novels are also tinged with magic featuring oriental magic realism, which is obviously influenced by Marquez. The magic and magnificent One Hundred Years 
of Solitude written by Marquez has amazed us by its quest for life and extremely exaggerated and magic technique. Mo Yan's novels also present such same characteristics, such as the wonderland of black child in Transparent Carrot, the fantastic world in Hell and the world of the living in Death are Wearing Me Out characterized by oriental magic. As a matter of fact, it is not uncommon to see magic in oriental culture. Chinese culture itself contains many supernatural stories, which is exclusive to the Orient. Mo Yan shows such magic technique in his works but doesn't deviate from reality, which is quite the same with the spirit of magic realism of Latin America. In addition, Mo Yan's novels, more often than not, overthrow the official historical record. The histories recorded in Red Sorghum, Sandalwood Death and Death are Wearing Me Out are not official ones. Such technique to overthrow official historical record and explore folk and marginal history is influenced by the wave of west neo-historicism. In Mo Yan's novels, characters are full of passion, the language style is used to its extreme and the rhetorical language is applied to break various conventional methods, which is similar with the carnival culture featuring Dionysian spirit of western culture in nature. Mo Yan is also good at creating a picturesque and vivid image world characterized by miracles and visual colors, which is affected by western painting technique. He likes Van Gogh's paintings very much. Thus, the techniques of intense colors and distorted style in drawing are used in his novels.

\section{Mo Yan's novels and cultural teaching in international Chinese education}

It is not successful for international Chinese education to simply teach Chinese as a foreign language and let foreigners master Chinese. In fact, it is more important to popularize and spread Chinese culture, build our cultural confidence in international stage and improve the soft power of Chinese culture through the promotion of Chinese. It is impossible to achieve such goals only by teaching. Therefore, it should make full use of those literary works full of Chinese culture to guide Chinese learners to get familiar with Chinese culture. And in the aspect of choosing literary works, on the one hand, it should take their cultural connotation into consideration and present excellent literary works with Chinese characteristics to Chinese learners; on the other hand, it should take account of diversification in the context of times and the acceptability of foreign learners. Mo Yan's novels unify the national and world characters in an harmonious manner, having both typical Chinese traditional and folk culture and global features and aesthetic characteristics to transcend time and space, geography and race, which is very suitable to be the cultural teaching materials for international Chinese education. Since most of Mo Yan's novels are full-length ones, which is not suitable to be taught in full text, we can choose short novels or readable excerpts from full-length novels or conduct theme-based teaching such the special subjects as "folk customs" and "Mo Yan and western writers" to cultivate their interest and thus guide them to read the full text of those works.

\section{CONCLUSION}

International Chinese education is an important channel to promote Chinese language, spread Chinese culture and build a cultural bridge between China and the West. Exchange and communication among different cultures can provide driving force to spread Chinese culture overseas and promote the development of Chinese culture in the cultural context of globalization. From China to western world, Mo Yan's novels have crossed cultural boundary, having oriental as well as global features and presenting the similarities among different cultures, which can promote cultural teaching in international Chinese education.

\section{REFERENCE}

[1] Cui Xiliang, International Chinese Education and Chinese Culture Going out[J].Applied Linguistics, 2012(02):25.

[2] $\mathrm{Xu}$ Lin, The Situation and Task to Promote Chinese[J].Chinese Teaching in the World, 2007(02):107.

[3] Shu Jinshu, Mo Yan, Local Characteristics is an Important Reason I Go Global[N]. People's Daily(Overseas Edition), 2012-10-9.

[4] Liu Yi, On Symbol Characteristic and Path Choice of Cross Culture Communication Based on Mo Yan's Prize-Winning[J],China Newspaper Industry, 2012(20):33.

[5] Ning Ming, Analysis on Creative Characteristics of Mo Yan from the Perspective of World Literature[J], Guansu Social Science, 2013(06):175.

[6] Wu Xiaoman, Mo Yan, I Am Not A Great Writer[N],China Times, 2005-1-30 